DOI: $10.20472 / I A C .2019 .048 .035$

\author{
JASSODRA MAHARAJ \\ UNIVERSITY OF EAST LONDON, United Kingdom
}

\title{
AN ANALYSIS INTO FDI AS A CONTRIBUTOR OF GROWTH AND DEVELOPMENT IN A GROUP OF A SELECTED SET OF COUNTRIES FROM ASIA, AFRICA AND SOUTH AMERICA
}

\begin{abstract}
:
Both the flow and stock of FDI grew very rapidly in the first part of the twentieth century but this was no match to the growth in FDI after the 2 nd World War. It is without doubt that the main mechanism of interconnectedness in the global economy has shifted from trade to FDI which has spread rapidly throughout the world dominating a wide range of industries. One of the most controversial issues is whether Foreign Direct Investment is beneficial to countries. Supporters of FDI (Rodrik, 2000) emphasize that growth is enhanced in the host country as FDI enables technology diffusion, enhances employment of human capital and allows host countries to gain access to wider global markets. On the other hand there is a substantial body of literature which emphasizes that FDI creates hardly any benefits to the host nation. It is often argued that the presence of plentiful and cheap labour is the main reason for attracting FDI. This study attempts to investigate whether FDI contributes to growth in a selected group of countries from Asia, Africa and South America using a panel data analysis. A panel data analysis is conducted for 12 countries in order to examine the effects of FDI, employment, and investment formation (lagged) on economic growth. The data for all variables are from the period from 1977 to 2016.
\end{abstract}

\section{Keywords:}

Foreign Direct Investment, growth, technology, panel

JEL Classification: F21, F23, F29 